\title{
Folate intake in a Swedish adult population: Food sources and predictive factors
}

\author{
Celia Monteagudo ${ }^{a, b}$, Henrik Scander ${ }^{c}, B$ Bente Nilsen ${ }^{c}$ and Agneta Yngve ${ }^{a}$

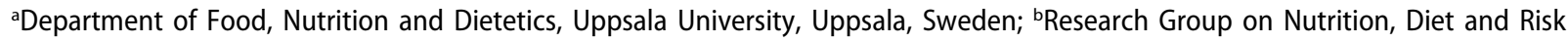 \\ Assessment-AGR255, Department of Nutrition and Food Science, University of Granada, Granada, Spain; 'School of Hospitality, Culinary Arts \\ and Meal Science, Örebro University, Örebro, Sweden
}

\begin{abstract}
Introduction: Folate plays an important role in cell metabolism, but international studies show that intake is currently below recommendations, especially among women. The study objective was to identify folate food sources by food group, gender, and age group, and to identify factors influencing folate intake, based on food consumption data for Swedish adults in the 2010-11 Riksmaten study.

Methods: The sample included a representative Swedish population aged $18-80$ years $(n=1657$; $56.3 \%$ female). Food and nutrient intakes were estimated from self-reported food records during 4 consecutive days. Food consumption was categorized into 26 food groups. Stepwise regression was used to analyze food groups as folate sources for participants. Factors predicting the highest folate intake (third tertile) were determined by logistic regression analysis.

Results: Vegetables and pulses represented the most important folate source for all age groups and both genders, especially in women aged $45-64$ years (49.7\% of total folate intake). The next folate source in importance was dairy products for the youngest group (18-30 years), bread for men, and fruit and berries for women. The likelihood of being in the highest tertile of folate intake (odds ratio $=1.69,95 \%$ confidence interval $1.354-2.104$ ) was higher for men. Influencing factors for folate intake in the highest tertile were low body mass index and high educational level in the men, and high educational level, vegetarian diet, organic product consumption, nonsmoking, and alcohol consumption within recommendations in the women.

Conclusion: This study describes the folate intake per food group of Swedish adults according to the 2010-11 Riksmaten survey, identifying vegetables and pulses as the most important source. Data obtained on factors related to folate consumption may be useful for the development of specific nutrition education programs to increase the intake of this vitamin in high-risk groups.
\end{abstract}

\section{ARTICLE HISTORY}

Received 23 December 2016

Accepted 26 April 2017

\section{KEYWORDS}

Dietary habits; Riksmaten

study; vegetable

consumption; lifestyle

habits; demographic

differences

\section{Introduction}

The biological activity of folate is related to the production and maintenance of new cells and is therefore in particular demand during periods of rapid cellular growth, such as pregnancy and childhood. Folate intake is also important to prevent cognitive decline in old age and may enhance academic performance in young people [1,2]. The recommended intake for adults is $400 \mu \mathrm{g} /$ day, with the addition of $200 \mu \mathrm{g} /$ day during pregnancy and $100 \mu \mathrm{g} /$ day during breastfeeding [3]. There is evidence that serum folate levels are reduced in smokers and alcohol drinkers $[4,5]$, who may therefore need a higher folate intake.

Current studies show that the folate intake of adults is below recommendations in several countries [6-9]. Food fortification plays an important role in this regard and is mandatory in many American and African countries [10]. Folic-acid fortified foods are also found in Europe (especially cereals), where this fortification is voluntary [11]; however, very few food products are fortified with folic acid in Sweden, where the policy is to recommend folic acid supplements to women planning a pregnancy.

The 2012 European Prospective Investigation into Cancer and Nutrition (EPIC) study in 10 European countries found the mean folate intake to be $307 \mu \mathrm{g} /$ day for men and $252 \mu \mathrm{g} / \mathrm{day}$ for women [12], while the estimated requirement is $320 \mu \mathrm{g} /$ day for either gender according to international recommendations $[13,14]$. Among participating countries, the highest intakes were in the UK, Spain, and France, while the lowest were in Sweden and Norway. The Riksmaten study of the food and nutrient intake in the Swedish population [15], on which the present article is based, found the intake of this vitamin to be higher

CONTACT Celia Monteagudo celiams@ugr.es E Department of Food, Nutrition and Dietetics, Uppsala University, Box 560, BMC Husargatan 3, SE-751 22 Uppsala, Sweden

(c) 2017 The Author(s). Published by Informa UK Limited, trading as Taylor \& Francis Group.

This is an Open Access article distributed under the terms of the Creative Commons Attribution License (http://creativecommons.org/licenses/by/4.0/), which permits unrestricted use, distribution, and reproduction in any medium, provided the original work is properly cited. 
than in previous years owing to an increase in fruit and vegetable consumption. The highest intake was among physically active participants, women with the highest income levels, and men with physically demanding work. The lowest intake was among smokers and among individuals in households with more than two people. The mean folate intake $(259 \pm 106 \mu \mathrm{g} /$ day $)$ was below the recommended level but met the average requirement established by Nordic Nutrition Recommendations [3]. Folate bioavailability depends on the food source and appears to be highest from fruit and vegetables, but limited data are available on this aspect [16]. The food matrix plays a very important role in this regard, and there is incomplete release of cell content from some plant cellular structures [17].

According to the food composition tables for Sweden, the richest sources of folate include liver, legumes, vegetables (mainly green leafy vegetables), fruit, and wholegrain cereals [18]. The 2010-11 Riksmaten survey provided the opportunity to determine the most important folate food sources in the Swedish population, analyzing patterns of consumption (amount, frequency, and food type) by subgroup (age, gender, educational level, and lifestyle). The objective of this study was to identify the most important folate food sources for adult participants in the 2010-11 Riksmaten study by gender and age group and to examine the relationship of demographic and lifestyle factors with their folate intake.

\section{Material and methods}

\section{Study population}

The study sample included a representative Swedish adult population aged 18-80 years from the Riksmaten study $(n=5000)$, previously described in detail by the Swedish National Food Agency [15]. The availability of food intake data from this study was the inclusion criterion for the present investigation ( $n=1797,56 \%$ women), while exclusion criteria were pregnancy $(n=25)$ and unknown gender $(n=115)$. The final study sample included 1657 participants $(56.3 \%$ women). The Riksmaten study was approved by the Regional Ethical Review Board of Uppsala, and all participants gave oral informed consent before entering the study.

\section{Dietetic and nutritional assessment}

Food and nutrient intakes were estimated from selfreported food records during 4 consecutive days, described in detail elsewhere [19]. Household measures, numbers of portions (cups, pieces, slices), and grams were used to estimate the amounts consumed [20].
Natural folate sources were studied by categorizing food consumption into 26 food groups, following $\mathrm{Ax}$ et al. [19]: fish and shellfish; meat and meat products; eggs; potatoes; vegetables and pulses; fruit and berries; dairy products; cream and crème frâiche; cheese; fast food; pasta, rice, and food grain; bread; cereals; sweet bakery products, sweets (candies), and chocolate; salads (vegetables mixed with cheese, poultry, pasta, bread, nuts, and sauces, among other foods); soups; sauces, dressings, and condiments; substitute products; fats; snacks; nuts and seeds; juice; coffee; tea; soda; and alcoholic beverages.

\section{Demographic, anthropometric, lifestyle, and food habit covariables}

Covariables were considered as dichotomized variables. Cut-off points were 50 years (median value) for age and a body mass index (BMI) of $25 \mathrm{~kg} / \mathrm{m}^{2}$ (underweight and normal weight vs overweight and obesity) based on selfreported height and weight. Education categories were grouped as higher (university and college) versus lower (3 years of high school, 2 years of high school, elementary school, and illiterate) levels. Food choice was described as vegetarianism (lactovegetarianism, lactovegetarianism including fish and eggs, ovolactovegetarianism, and veganism) versus the eating of all types of food. Special diets considered included those for food intolerance/allergy, weight loss, and the treatment of disease (e.g. diabetes or dyslipidemia). Consumption of organically grown fruit and vegetables was dichotomized as frequent versus occasional or no consumption. Alcohol intake was divided according to the Nordic Nutritional Recommendations [3] between $<20 \mathrm{~g} /$ day for men or $<10 \mathrm{~g} /$ day for women and $\geq 20 \mathrm{~g} /$ day or $\geq 10 \mathrm{~g} /$ day, respectively. Smoking was dichotomized as daily versus occasional or no smoking.

\section{Statistical analysis}

Means with standard deviation (SD) were calculated for quantitative variables and frequencies (\%) for nominal variables. The Student's $t$, Pearson's chi-squared, and analysis of variance (ANOVA) tests were used to study differences by gender and folate intake tertile. Stepwise linear regression [21,22] was performed to analyze folate sources for the Swedish population, with total folate intake ( $\mu \mathrm{g} /$ day) as the dependent variable and folate intake ( $\mu \mathrm{g} /$ day) from the 26 aforementioned food groups as factors. The distribution of demographics, lifestyle, and dietary data was assessed by tertile of folate intake. Factors predicting the highest folate intake (third tertile) were determined by logistic regression analysis, including the aforementioned 
covariables (gender, age, BMI, educational level, vegetarian, special diet, consumption of organic fruit and vegetables, nutritional supplementation, smoking, and alcohol intake) in the model. $p<0.05$ was considered significant. SPSS version 22 (IBM Corp., Armonk, NY, USA) was used for statistical analyses.

\section{Results}

Table 1 exhibits the general characteristics of the study population (Table 1). The mean age was around 50 years and the mean (SD) BMI was within the overweight range. The educational level was high, especially for the women, $45 \%$ of whom had studied at university. There was a low frequency of vegetarianism and weight-loss diets, while more than $40 \%$ of participants consumed organic fruit and vegetables and almost 50\% took nutritional supplements. Overall, $16.2 \%$ of participants were smokers, with no difference between the genders $(p=0.529)$; alcohol intake was significantly higher in men than in women $(p<0.001)$.

Table 2 shows the food consumption for men and women by food group. Women reported a higher frequency of all food groups (\%), while men reported a significantly higher intake (g/day) of all food groups with the exception of vegetables/beans and fruit/berries, the intake of which was significantly greater in women.
Table 1. General characteristics of the study population.

\begin{tabular}{|c|c|c|c|c|}
\hline & $\begin{array}{c}\text { Total } \\
(n=1657)\end{array}$ & $\begin{array}{c}\text { Men } \\
(n=724)\end{array}$ & $\begin{array}{l}\text { Women } \\
(n=933)\end{array}$ & $\boldsymbol{p}^{\mathrm{a}}$ \\
\hline \multicolumn{5}{|l|}{ Age (years) } \\
\hline Mean & 49.61 & 50.87 & 48.64 & $0.007^{b}$ \\
\hline SD & 16.59 & 16.31 & 16.74 & \\
\hline \multicolumn{5}{|c|}{ Body mass index $\left(\mathrm{kg} / \mathrm{m}^{2}\right)$} \\
\hline Mean & 25.46 & 26.05 & 25.00 & $<0.001^{b}$ \\
\hline SD & 4.34 & 3.82 & 4.57 & \\
\hline \multicolumn{5}{|c|}{ Educational level (\%) } \\
\hline University & 42.5 & 38.3 & 45.7 & 0.002 \\
\hline Non-university & 57.5 & 61.7 & 54.3 & \\
\hline \multicolumn{5}{|l|}{ Vegetarian (\%) } \\
\hline Yes & 4.8 & 3.2 & 6.1 & 0.006 \\
\hline \multicolumn{5}{|l|}{ Diet (\%) } \\
\hline Yes & 5.4 & 4.9 & 5.9 & 0.385 \\
\hline \multicolumn{5}{|l|}{$\begin{array}{l}\text { Organic fruit and } \\
\text { vegetables (\%) }\end{array}$} \\
\hline Yes & 42.2 & 39.9 & 44.1 & 0.086 \\
\hline \multicolumn{5}{|c|}{$\begin{array}{l}\text { Nutritional supplements } \\
(\%)\end{array}$} \\
\hline Yes & 49.4 & 41.3 & 55.7 & $<0.001$ \\
\hline \multicolumn{5}{|c|}{ Alcohol intake (g/day) } \\
\hline Mean & 9.41 & 11.95 & 7.46 & $<0.001^{b}$ \\
\hline SD & 12.25 & 13.92 & 10.39 & \\
\hline \multicolumn{5}{|l|}{ Smoking (\%) } \\
\hline Yes & 16.2 & 15.5 & 16.7 & 0.529 \\
\hline
\end{tabular}

${ }^{a}$ Chi-squared test.

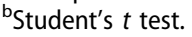

Folate sources by age group and gender are displayed in Tables 3 (for women) and 4 (for men). The model for women, which included 18 of the 26 food groups, explained more than $93 \%$ of the total folate intake; the main folate source was vegetables and pulses, which provided $49.7 \%$ of the total folate intake in women

Table 2. Percentage of participants who consumed each food group, and grams per day consumed for men and women.

\begin{tabular}{|c|c|c|c|c|c|c|c|}
\hline \multirow[b]{2}{*}{ Food groups } & \multicolumn{3}{|c|}{ Men $(n=724)$} & \multicolumn{3}{|c|}{ Women $(n=933)$} & \multirow[b]{2}{*}{$p^{\mathrm{b}}$} \\
\hline & $\%$ & Mean $^{\mathrm{a}}$ & SD & $\%$ & Mean $^{a}$ & SD & \\
\hline Fish and shellfish/seafood & 30.4 & 71.93 & 50.72 & 43.2 & 55.30 & 38.81 & $<0.001$ \\
\hline Meat and meat products & 42.2 & 149.54 & 79.70 & 53.9 & 107.07 & 58.20 & $<0.001$ \\
\hline Eggs & 22.0 & 36.55 & 29.68 & 31.5 & 35.59 & 28.41 & 0.626 \\
\hline Potatoes & 43.0 & 139.04 & 105.07 & 56.3 & 79.91 & 70.70 & $<0.001$ \\
\hline Vegetables and pulses & 40.6 & 124.33 & 87.50 & 54.8 & 142.03 & 88.69 & $<0.001$ \\
\hline Fruit and berries & 34.3 & 137.67 & 106.16 & 51.5 & 162.62 & 106.68 & $<0.001$ \\
\hline Milk products & 38.0 & 289.24 & 191.46 & 51.3 & 243.39 & 156.13 & $<0.001$ \\
\hline Cream and crème fraîche & 12.4 & 20.68 & 16.72 & 21.9 & 18.25 & 15.81 & 0.086 \\
\hline Cheese & 36.6 & 28.18 & 21.83 & 50.6 & 26.28 & 22.39 & 0.107 \\
\hline Fast food & 18.6 & 119.65 & 76.74 & 20.6 & 89.08 & 60.73 & $<0.001$ \\
\hline Pasta, rice, and grain & 32.8 & 109.15 & 71.92 & 43.5 & 80.44 & 57.81 & $<0.001$ \\
\hline Bread & 42.8 & 99.69 & 51.50 & 55.2 & 73.97 & 39.27 & $<0.001$ \\
\hline Cereals & 28.8 & 78.56 & 76.20 & 39.3 & 63.11 & 65.36 & $<0.001$ \\
\hline Sweet bakery products and sweets & 38.0 & 80.92 & 60.55 & 52.0 & 66.63 & 49.70 & $<0.001$ \\
\hline Salads & 8.8 & 73.72 & 39.99 & 12.3 & 68.46 & 40.21 & 0.228 \\
\hline Soups & 12.6 & 110.38 & 59.77 & 17.4 & 90.32 & 56.09 & $<0.001$ \\
\hline Sauces, dressings, and condiments & 33.1 & 47.40 & 38.18 & 46.5 & 38.84 & 33.93 & $<0.001$ \\
\hline Substitute products & 1.7 & 77.96 & 63.84 & 3.3 & 96.83 & 83.75 & 0.299 \\
\hline Fats & 35.8 & 16.02 & 10.91 & 47.6 & 12.02 & 8.76 & $<0.001$ \\
\hline Snacks & 8.7 & 16.76 & 13.69 & 13.7 & 11.36 & 12.49 & $<0.001$ \\
\hline Nuts and seeds & 8.3 & 18.46 & 14.00 & 17.9 & 15.04 & 12.35 & 0.010 \\
\hline Juice & 19.5 & 143.71 & 100.07 & 23.2 & 120.73 & 90.29 & 0.002 \\
\hline Coffee & 37.2 & 441.65 & 247.99 & 45.8 & 406.12 & 224.67 & 0.006 \\
\hline Tea & 16.8 & 236.76 & 186.96 & 31.4 & 260.84 & 237.37 & 0.116 \\
\hline Soda & 23.3 & 213.05 & 180.29 & 28.2 & 181.55 & 159.55 & 0.008 \\
\hline Alcoholic beverages & 28.4 & 273.82 & 204.87 & 31.4 & 176.04 & 142.77 & $<0.001$ \\
\hline
\end{tabular}

${ }^{\mathrm{a}}$ Mean (g/day) intake for individuals reporting consumption of the item.

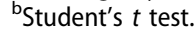


Table 3. Folate sources by age group for women (stepwise regression analysis).

\begin{tabular}{|c|c|c|c|c|c|}
\hline $18-30$ years & $\% R^{2}$ & Change in $R^{2}$ & $31-44$ years & $\% R^{2}$ & Change in $R^{2}$ \\
\hline Vegetables and pulses & 37.8 & 37.8 & Vegetables and pulses & 49.1 & 49.1 \\
\hline Milk products & 54.8 & 17.0 & Fruit and berries & 63.1 & 14.0 \\
\hline Bread & 62.9 & 8.0 & Bread & 70.9 & 7.8 \\
\hline Fruit and berries & 69.9 & 7.0 & Milk products & 76.5 & 5.6 \\
\hline Juice & 74.8 & 4.9 & Potatoes & 80.2 & 3.7 \\
\hline Eggs & 78.9 & 4.2 & Fast food & 83.2 & 3.0 \\
\hline Fast food & 82.6 & 3.7 & Juice & 85.6 & 2.3 \\
\hline Fish and shellfish/seafood & 85.3 & 2.7 & Eggs & 87.6 & 2.0 \\
\hline Nuts and seeds & 87.3 & 1.9 & Substitute products & 89.2 & 1.6 \\
\hline Potatoes & 89.2 & 1.9 & Salads & 90.4 & 1.2 \\
\hline Tea & 90.7 & 1.5 & Soups & 91.6 & 1.2 \\
\hline Substitute products & 91.6 & 0.9 & Meat & 92.6 & 1.0 \\
\hline Cheese & 92.5 & 0.9 & Fish and shellfish/seafood & 93.4 & 0.8 \\
\hline \multirow[t]{3}{*}{ Meat } & 93.3 & 0.8 & Nuts and sees & 94.1 & 0.7 \\
\hline & & & Pasta, rice, and grain & 94.5 & 0.4 \\
\hline & & & Sweet bakery products and sweets & 94.7 & 0.1 \\
\hline 45-64 years & $\% R^{2}$ & Change in $R^{2}$ & $>64$ years & $\% R^{2}$ & Change in $R^{2}$ \\
\hline Vegetables and pulses & 49.7 & 49.7 & Vegetables and pulses & 44.7 & 44.7 \\
\hline Fruit and berries & 62.5 & 12.8 & Fruit and berries & 61.5 & 16.9 \\
\hline Bread & 70.6 & 8.1 & Juice & 70.6 & 9.1 \\
\hline Milk products & 75.2 & 4.6 & Bread & 76.6 & 6.0 \\
\hline Juice & 79.4 & 4.1 & Milk products & 81.8 & 5.2 \\
\hline Eggs & 82.9 & 3.5 & Potatoes & 85.8 & 4.0 \\
\hline Potatoes & 85.5 & 2.6 & Soups & 88.6 & 2.8 \\
\hline Fast food & 87.8 & 2.2 & Eggs & 90.7 & 2.1 \\
\hline Tea & 89.9 & 2.1 & Nuts and seeds & 92.0 & 1.2 \\
\hline Nuts and seeds & 91.1 & 1.2 & Fish and shellfish/seafood & 92.8 & 0.9 \\
\hline Soups & 92.3 & 1.2 & Tea & 93.7 & 0.9 \\
\hline Meat & 93.5 & 1.2 & Meat & 94.6 & 0.8 \\
\hline Salads & 94.7 & 1.2 & Fast food & 95.6 & 1.0 \\
\hline Fish and shellfish/seafood & 95.6 & 0.9 & Cheese & 96.3 & 0.7 \\
\hline Cheese & 96.1 & 0.5 & & & \\
\hline Sweet bakery products and sweets & 96.3 & 0.1 & & & \\
\hline
\end{tabular}

The cut-off $p$ value for entry into the equation was $p=0.017$ for the $18-30$ year age group, $p=0.043$ for the 31-44 year group, $p=0.005$ for the $45-64$ year group, and $p=0.012$ for the $>64$ year age group.

aged 45-64 years. The second folate source was fruit and berries for all age groups with the exception of the youngest women, for whom it was milk products. Salads and pasta, rice, and grains only entered the model for women aged 31-44 years. In accordance with Ax et al. [19], salads were not considered in the vegetables/bean group because they often include not only vegetables (e.g. lettuce and cucumber) but also non-vegetable ingredients such as cheese, poultry, pasta, bread, and sauces, among others. The model for men, which included 20 of the 26 food groups, explained $93 \%$ of the total folate intake. As for the women, vegetables and pulses were the primary folate source for men but made a lesser contribution to total folate intake. Fruit and berries were only the second most important source for men aged over 64 years, while milk products and bread made a greater contribution to total folate intake in men than in women.

The age was significantly higher for those in the highest (third) folate intake tertile, while the BMI was significantly higher for those in the lowest (first) intake tertile among the men alone. High versus low education was significantly more frequent in the highest folate intake tertile for both genders, while adherence to a vegetarian diet and consumption of organic products were significantly more frequent in the third tertile for the women alone. Smoking was significantly more frequent in the lowest folate intake tertile for both genders (Table 5).

Table 6 shows factors related to folate intake (3rd tertile) for the study population. Globally, the probability of reaching the highest tertile of folate intake was higher for men than for women. BMI $<25 \mathrm{~kg} / \mathrm{m}^{2}$ and university education were positively related to folate intake in men. Among women, the probability of reaching the highest tertile of folate intake was higher for over 50-year-olds and for those with high educational level who followed a vegetarian diet, consumed organic products, and did not smoke, and whose alcohol intake was $<10 \mathrm{~g} /$ day.

\section{Discussion}

This study determined the folate sources of a representative sample of Swedish adults and analyzed the factors that influenced their intake of this vitamin. Vegetables and pulses were found to be the main folate source, and made a higher contribution to 
Table 4. Folate sources by age group for men (stepwise regression analysis).

\begin{tabular}{|c|c|c|c|c|c|}
\hline $18-30$ years & $\% R^{2}$ & Change in $R^{2}$ & $31-44$ years & $\% R^{2}$ & Change in $R^{2}$ \\
\hline Vegetables and pulses & 30.3 & 30.3 & Vegetables and pulses & 33.9 & 33.9 \\
\hline Milk products & 42.7 & 13.5 & Bread & 46.4 & 12.6 \\
\hline Juice & 54.8 & 12.3 & Potatoes & 55.1 & 8.7 \\
\hline Bread & 61.6 & 7.0 & Fast food & 63.1 & 8.3 \\
\hline Substitute products & 67.3 & 5.8 & Milk products & 70.4 & 6.9 \\
\hline Potatoes & 73.1 & 5.8 & Fruit and berries & 75.6 & 5.2 \\
\hline Fast food & 78.2 & 5.1 & Juice & 80.7 & 5.0 \\
\hline Eggs & 82.5 & 4.3 & Sweet bakery products and sweets & 83.7 & 3.1 \\
\hline Fruit and berries & 86.5 & 4.0 & Cereals & 86.7 & 3.0 \\
\hline Meat & 88.4 & 1.9 & Eggs & 89.0 & 2.3 \\
\hline Tea & 90.3 & 1.9 & Meat & 91.3 & 2.2 \\
\hline Cheese & 91.5 & 1.2 & Soups & 92.6 & 1.3 \\
\hline \multirow[t]{3}{*}{ Sweet bakery products and sweets } & 92.1 & 0.6 & Fish and shellfish/seafood & 93.9 & 1.3 \\
\hline & & & Salads & 95.0 & 1.1 \\
\hline & & & Nuts and seeds & 95.7 & 0.7 \\
\hline 45-64 years & $\% R^{2}$ & Change in $R^{2}$ & $>64$ years & $\% R^{2}$ & Change in $R^{2}$ \\
\hline Vegetables and pulses & 44.0 & 44.0 & Vegetables and pulses & 37.3 & 37.3 \\
\hline Bread & 57.9 & 13.9 & Fruit and berries & 51.4 & 14.2 \\
\hline Milk products & 70.1 & 12.2 & Bread & 63.5 & 12.1 \\
\hline Potatoes & 75.5 & 5.5 & Juice & 72.0 & 8.5 \\
\hline Juice & 80.4 & 4.8 & Potatoes & 79.3 & 7.2 \\
\hline Fruit and berries & 82.8 & 2.5 & Milk products & 84.5 & 5.3 \\
\hline Fast food & 85.1 & 2.3 & Fast food & 86.5 & 2.0 \\
\hline Eggs & 87.3 & 2.2 & Fish and shellfish/seafood & 88.1 & 1.6 \\
\hline Cereals & 89.5 & 2.2 & Nuts and seeds & 89.2 & 1.1 \\
\hline Nuts and seeds & 91.3 & 1.8 & Soups & 90.5 & 1.3 \\
\hline Fish and shellfish/seafood & 92.8 & 1.5 & Tea & 91.5 & 1.0 \\
\hline Cheese & 93.9 & 1.1 & Meat & 92.3 & 0.8 \\
\hline Sauces, dressings, and condiments & 94.7 & 0.8 & Cheese & 92.9 & 0.6 \\
\hline Tea & 95.4 & 0.7 & Salads & 93.2 & 0.3 \\
\hline Soups & 96.0 & 0.6 & & & \\
\hline Salads & 96.6 & 0.6 & & & \\
\hline Pasta, rice and grain & 97.0 & 0.5 & & & \\
\hline Sweet bakery products and sweets & 97.4 & 0.3 & & & \\
\hline Fats & 97.4 & 0.1 & & & \\
\hline
\end{tabular}

Table 5. Demographic, lifestyle, and dietary factors per tertile (T) of folate intake for men and women.

\begin{tabular}{|c|c|c|c|c|c|c|}
\hline & \multicolumn{3}{|c|}{ Men $(n=724)$} & \multicolumn{3}{|c|}{ Women $(n=933)$} \\
\hline & T1 & $\mathrm{T} 2$ & T3 & $\mathrm{T} 1$ & $\mathrm{~T} 2$ & $\mathrm{~T} 3$ \\
\hline & \multicolumn{6}{|c|}{ Mean (SD) } \\
\hline $\begin{array}{l}\text { Folate intake } \\
(\mu \mathrm{d} / \text { day })^{\mathrm{a}, \mathrm{b}}\end{array}$ & $\begin{array}{c}151.75 \\
(33.70)\end{array}$ & $\begin{array}{c}227.64 \\
(18.87)\end{array}$ & $\begin{array}{c}316.46 \\
(48.62)\end{array}$ & $\begin{array}{l}153.09 \\
(32.84)\end{array}$ & $\begin{array}{c}224.90 \\
(17.80)\end{array}$ & $\begin{array}{c}313.91 \\
(46.53)\end{array}$ \\
\hline Age (years) ${ }^{a, b}$ & $\begin{array}{c}49.18 \\
(18.06)\end{array}$ & $\begin{array}{l}52.18 \\
(17.00)\end{array}$ & $\begin{array}{c}52.22 \\
(16.49)\end{array}$ & $\begin{array}{l}46.81 \\
(18.04)\end{array}$ & $\begin{array}{c}47.74 \\
(16.32)\end{array}$ & $\begin{array}{c}51.29 \\
(16.78)\end{array}$ \\
\hline $\begin{array}{l}\text { Body mass index } \\
\left(\mathrm{kg} / \mathrm{m}^{2}\right)^{\mathrm{a}}\end{array}$ & $\begin{array}{c}26.64 \\
(3.76)\end{array}$ & $\begin{array}{l}25.99 \\
(3.89)\end{array}$ & $\begin{array}{l}25.68 \\
(3.77)\end{array}$ & $\begin{array}{c}25.09 \\
(4.94)\end{array}$ & $\begin{array}{l}25.27 \\
(4.56)\end{array}$ & $\begin{array}{c}24.61 \\
(4.37)\end{array}$ \\
\hline \multirow[t]{2}{*}{$\begin{array}{l}\text { Alcohol intake } \\
\text { (g/day) }\end{array}$} & $\begin{array}{c}15.59 \\
(13.64)\end{array}$ & $\begin{array}{c}19.69 \\
(15.26)\end{array}$ & $\begin{array}{l}18.70 \\
(14.64)\end{array}$ & $\begin{array}{c}14.60 \\
(12.12)\end{array}$ & $\begin{array}{c}14.03 \\
(11.05)\end{array}$ & $\begin{array}{l}11.85 \\
(9.81)\end{array}$ \\
\hline & \multicolumn{6}{|c|}{$\%$} \\
\hline $\begin{array}{l}\text { Higher education } \\
\text { (university) }^{c, d}\end{array}$ & 23.6 & 30.1 & 46.4 & 27.5 & 36.6 & 35.9 \\
\hline Vegetarian $^{\text {d }}$ & 21.7 & 21.7 & 56.5 & 24.1 & 25.9 & 50.0 \\
\hline Diet & 45.7 & 25.7 & 28.6 & 38.2 & 30.9 & 30.9 \\
\hline $\begin{array}{l}\text { Organic fruit and } \\
\text { vegetables }^{\mathrm{d}}\end{array}$ & 29.0 & 29.7 & 41.3 & 30.6 & 32.7 & 36.7 \\
\hline $\begin{array}{l}\text { Nutritional } \\
\text { supplements }\end{array}$ & 26.4 & 35.6 & 38.0 & 32.8 & 34.0 & 33.2 \\
\hline Smoking ${ }^{c, d}$ & 45.5 & 19.6 & 34.8 & 51.0 & 32.9 & 16.1 \\
\hline
\end{tabular}

ANOVA test: ${ }^{a} p<0.05$ for men; ${ }^{b} p<0.05$ for women.

Chi-squared test: ${ }^{c} p<0.05$ for men; ${ }^{d} p<0.05$ for women.

total intake in women than in men. Similar results were published by Park et al. [12] in a study across 10 European countries (Denmark, France, Greece,
Germany, Italy, The Netherlands, Norway, Spain, Sweden, and the UK), in which vegetables were the first folate source but made a lower percentage contribution (20.8\% for men and $25.2 \%$ for women) than in the present population. The European study also described differences between the more southerly countries, in which fruit and leafy vegetables were the major vegetable source of folate, and the more northerly countries, in which cabbages and root vegetables were the major vegetable source. Vegetables were the main folate source for pregnant women in Germany, Spain, and Hungary, contributing to $31.2 \%$, $23.4 \%$, and $30.0 \%$ of their total folate intake, respectively [23]. However, another study of a sample of young male adults in Norway highlighted that wholegrain bread was the main contributor (around 50\%) to total folate intake [24]. More recently, Pounis et al. [25] showed that potatoes and bread were the main sources (contributing to $61.5 \%$ of the total folate intake) for participants from Italy, whereas broccoli and root vegetables were the most important contributors $(59.1 \%$ of total folate intake) for those from the UK. 
Table 6. Predictive factors for the highest folate intake (third tertile) for the Riksmaten 2010-11 population.

\begin{tabular}{|c|c|c|c|c|c|c|c|}
\hline & & $\%$ & OR & $95 \% \mathrm{Cl}$ & & & \\
\hline \multirow[t]{4}{*}{ Gender (all participants) } & Women & 56.3 & Ref. & & & & \\
\hline & Men & & 1.69 & $1.354-2.104$ & & & \\
\hline & & \multicolumn{3}{|c|}{ Men } & \multicolumn{3}{|c|}{ Women } \\
\hline & & $\%$ & OR & $95 \% \mathrm{Cl}$ & $\%$ & OR & $95 \% \mathrm{Cl}$ \\
\hline \multirow[t]{2}{*}{ Age } & $\leq$ Median (50 years) & 48.5 & Ref. & & 52.5 & Ref. & \\
\hline & $>$ Median (50 years) & & 1.28 & $0.922-1.773$ & & 1.67 & $1.233-2.264$ \\
\hline \multirow[t]{2}{*}{ Body mass index } & $<25 \mathrm{~kg} / \mathrm{m}^{2}$ & 44.4 & 1.52 & $1.101-2.089$ & 60.6 & 1.30 & $0.950-1.778$ \\
\hline & $\geq 25 \mathrm{~kg} / \mathrm{m}^{2}$ & & Ref. & & & Ref. & \\
\hline \multirow[t]{2}{*}{ Educational level } & University & 38.3 & 1.60 & $1.153-2.207$ & 45.7 & 1.52 & $1.127-2.059$ \\
\hline & Non-university & & Ref. & & & Ref. & \\
\hline \multirow[t]{2}{*}{ Vegetarian } & Yes & 3.2 & 2.20 & $0.890-5.434$ & 6.1 & 2.23 & $1.246-3.988$ \\
\hline & No & & Ref. & & & Ref. & \\
\hline \multirow[t]{2}{*}{ Diet } & Yes & 4.9 & Ref. & & 5.9 & Ref. & \\
\hline & No & & 1.52 & $0.694-3.342$ & & 1.10 & $0.585-2.078$ \\
\hline \multirow[t]{2}{*}{ Organic fruit and vegetables } & Yes & 39.9 & 1.19 & $0.854-1.625$ & 44.1 & 1.55 & $1.157-2.088$ \\
\hline & No & & Ref. & & & Ref. & \\
\hline \multirow[t]{2}{*}{ Nutritional supplements } & Yes & 41.3 & 0.94 & $0.684-1.302$ & 55.7 & 1.30 & $0.964-1.748$ \\
\hline & No & & Ref. & & & Ref. & \\
\hline \multirow{2}{*}{ Smoking } & Smoking & 15.5 & Ref. & & 16.7 & Ref. & \\
\hline & Non-smoking & & 1.28 & $0.819-2.003$ & & 2.30 & $1.431-3.707$ \\
\hline \multirow[t]{2}{*}{ Alcohol intake } & $=$ Recommended $^{\mathrm{a}}$ & 73.9 & 0.73 & $0.514-1.043$ & 71.6 & 1.42 & $1.012-1.983$ \\
\hline & $>$ Recommended $^{\mathrm{a}}$ & & Ref. & & & Ref. & \\
\hline
\end{tabular}

${ }^{\mathrm{a}}$ Recommended alcohol intake according to Nordic Nutrition Recommendations [3]: $<10 \mathrm{~g} /$ day for women and $<20 \mathrm{~g} /$ day for men. $\mathrm{OR}$, odds ratio; $\mathrm{Cl}$, confidence interval.

According to our results in Sweden, other important folate sources were fruit and berries, bread, dairy products, potatoes, and juice. The consumption of fruit and berries was significantly lower in men than in women, in agreement with a previous national food intake survey [26], which may explain why this food group provided less than $5 \%$ of the total folate intake for men aged under 65 years but more than $12.8 \%$ of the intake for women aged over 30 years. Dairy products were the second folate source for the youngest men and women, which can be especially attributed to their consumption of fermented products such as yogurt [27].

Our analysis of the variables influencing a high intake of folate by this adult population found that gender was a significant factor, with the likelihood of an intake in the highest tertile being 1.69-fold higher for the men than for the women. According to the Riksmaten study [15], men had a higher energy and nutrient intake (except for fiber, vitamin $\mathrm{A}$, and vitamin C) owing to a higher consumption of almost all food groups (Table 2). Among the men, participants with a BMI $>25 \mathrm{~kg} / \mathrm{m}^{2}$ had a lower likelihood of reaching the highest tertile of folate intake than those with lower BMI. Dietary patterns with a high intake of folate-rich foods (vegetables, pulses, cereals, and fruit) have shown a protective effect against the risk of becoming overweight or obese [28].

In the present investigation, men and women with a university education had a higher probability of folate intake in the highest tertile. Current studies [29,30] have shown a more frequent consumption of fruit and vegetables by individuals with a high versus a low educational level. The present participants with a high educational level reported a significantly higher intake of vegetables and pulses than those with a lower educational level $(p<0.05)$, whereas no significant differences were observed for fruit and berry consumption $(p=0.054)$.

The folate intake by women was influenced by other factors, with those aged $>50$ years having a greater likelihood of being in the highest tertile of folate intake, consistent with previous findings for women in southern Spain [31]. This may be attributable to a closer adherence to traditional dietary patterns, in which there is a greater consumption of vegetables, pulses, fruit, and cereals [32,33]. Various authors have reported a higher folate intake among people who follow vegetarian and vegan diets [34-36], and the folate intake was $30 \mu \mathrm{g} /$ day higher for vegetarian women $(p=0.021)$ in the present investigation, although no such difference was observed for the men ( $p=0.123$ ). Furthermore, the likelihood of being in the highest tertile of folate intake was 1.5 -fold greater for the women who consumed organic foods, which may be due to a more frequent consumption of plant foods among individuals interested in organically grown food [37].

Smoking and alcohol intake were found to be related to the folate intake of women. Female smokers had a higher risk of being in the lowest tertile of folate intake. Some authors attributed a lower serum folate level in smokers to the interaction of chemical compounds in tobacco with 
folate and other vitamins $\left(\mathrm{B}_{6}\right.$ and $\left.\mathrm{B}_{12}\right)[4,38]$, transforming them into inactive compounds and reducing their availability. Alcohol intake has also been reported to have detrimental effects on folate absorption [5]. The present findings suggest the need to provide additional information on folate-rich foods to young women who smoke and/or consume large amounts of alcohol, although further research is required to explore the relationship of folate intake with tobacco and alcohol consumption.

This study was performed over an entire calendar year and should therefore take account of seasonal variations. It also used a previously tested battery of survey tools and included participants from all parts of Sweden and all types of living environment, including large and small cities as well as rural settings.

However, there was a large number of dropouts from the study, which was completed by only $36 \%$ of the initial target population. There were also indications that the intake of fruit and berries may have been lower in nonrespondents than in respondents. The food database used also has some shortcomings and does not take account of variations in folate content according to season, storage, and cooking. Hence, these results are only indicative of the highest intakes, and it should also be borne in mind that the issue of bioavailability is not considered.

In conclusion, this study of the folate intake of Swedish adults, based on the Riksmaten survey in 2010-11, identifies vegetables and pulses as the most important folate source. Data obtained on factors related to folate consumption, including gender, age, lifestyle, and dietary habits, may provide useful background information for the development of specific nutrition education programs to increase the intake of this vitamin in high-risk groups.

\section{Acknowledgements}

We thank our colleagues at the Swedish National Food Agency who let us use the material for this publication. Also, we would like to express our gratitude for the efforts of all participants in the Riksmaten study 2010-11. This work is a part of the postdoctoral research stay of Celia Monteagudo, funded by the University of Granada and applied at Uppsala University.

\section{Disclosure statement}

No potential conflict of interest was reported by the authors.

\section{Funding}

This work was supported by the University of Granada.

\section{References}

[1] Horvat P, Gardiner J, Kubinova R, et al. Serum folate, vitamin B-12 and cognitive function in middle and older age: the HAPIEE study. Exp Gerontol. 2016 Apr;76:33-38. DOI:10.1016/j.exger.2016.01.011

[2] Nilsson TK, Yngve A, Böttiger AK, et al. High folate intake is related to better academic achievement in Swedish adolescents. Pediatrics. 2011 Aug;128(2):e358e365.

[3] Nordic Nutrition Recommendations 2012. Integrating nutrition and physical activity. Copenhagen: Nordic Council of Ministers; 2014.

[4] Vardavas CI, Linardakis MK, Hatzis CM, et al. Smoking status in relation to serum folate and dietary vitamin intake. Tob Induc Dis. 2008 Sep 9;4:8.

[5] Persson EC, Schwartz LM, Park Y, et al. Alcohol consumption, folate intake, hepatocellular carcinoma, and liver disease mortality. Cancer Epidemiol Biomarkers Prev. 2013 Mar;22(3):415-421.

[6] Mensink GB, Fletcher R, Gurinovic M, et al. Mapping low intake of micronutrients across Europe. Br J Nutr. 2013 Aug;110(4):755-773.

[7] Gong Z, Ambrosone CB, McCann SE, et al. Associations of dietary folate, vitamins B6 and B12 and methionine intake with risk of breast cancer among African American and European American women. Int J Cancer. 2014 Mar 15;134(6):1422-1435.

[8] Shahab-Ferdows S, Engle-Stone R, Hampel D, et al. Regional, socioeconomic, and dietary risk factors for Vitamin B-12 deficiency differ from those for folate deficiency in Cameroonian women and children. J Nutr. 2015 Nov;145(11):2587-2595. DOI:10.3945/ jn.115.210195

[9] Zheng J-S, Guan Y, Zhao Y, et al. Pre-conceptional intake of folic acid supplements is inverselyassociated with risk of preterm birth and small-for-gestational-age birth: aprospective cohort study. Br J Nutr. 2016 Feb 14;115(3):509-516. DOI:10.1017/S0007114515004663

[10] Food Fortification Initiative. Enhancing grains for healthier lives. Country profiles. [cited 2017 Jan]. Available from: http://www.ffinetwork.org/country_profiles/ index.php

[11] EFSA. ESCO report: prepared by the EFSA scientific cooperation working group on analysis of risks and benefits of fortification of food with folic acid. 2009.

[12] Park JY, Nicolas G, Freisling H, et al. Comparison of standardised dietary folate intake across ten countries participating in the European Prospective Investigation into Cancer and Nutrition. Br J Nutr. 2012;108:552-569.

[13] Dietary reference intakes for calcium, phosphorus, magnesium, vitamin D, and fluoride (1997); Dietary reference intakes for thiamin, riboflavin, niacin, vitamin B6, folate, vitamin B12, pantothenic acid, biotin, and choline (1998); Dietary reference intakes for vitamin C, vitamin E, selenium, and carotenoids (2000); Dietary reference intakes for vitamin $\mathrm{A}$, vitamin $\mathrm{K}$, arsenic, boron, chromium, copper, iodine, iron, manganese, molybdenum, nickel, silicon, vanadium, and zinc (2001); Dietary reference intakes for energy, carbohydrate, fiber, fat, fatty acids, cholesterol, protein, and amino acids (2002/2005); and Dietary reference intakes 
for calcium and vitamin D (2011). These reports may be accessed via www.nap.edu

[14] WHO/FAO (World Health Organization/Food and Agriculture Organization of the United Nations). Vitamin and mineral requirements in human nutrition: report of a joint FAO/WHO expert consultation. Folate and folic acid. 1998 Sep 21-30; Bangkok, Thailand; 2004. 341 pp.

[15] Swedish National Food Agency. Riksmaten 2010-11, Livsmedels- och näringsintag bland vuxna i Sverige [Riksmaten 2010-11, intake of foods and nutrients among adults in Sweden]. Uppsala: National Food Agency; 2012. Swedish. Available from: www.livsmedels verket.se/globalassets/matvanor-halsa-miljo/kostradmatvanor/matvaneundersokningar/riksmaten_2010_ 20111.pdf

[16] Ohrvik VE, Witthoft CM. Human folate bioavailability. Nutrients. 2011 Apr;3(4):475-490.

[17] Castenmiller JJ, van de Poll CJ, West CE, et al. Bioavailability of folate from processed spinach in humans. Effect of food matrix and interaction with carotenoids. Ann Nutr Metab. 2000;44(4):163-169.

[18] Swedish Food Composition Database (Reviewed 2015-0309). Available from: http://www.livsmedelsverket.se/en/ food-and-content/naringsamnen/livsmedelsdatabasen/

[19] Ax E, Warensjö Lemming E, Becker W, et al. Dietary patterns in Swedish adults; results from a national dietary survey. Br J Nutr. 2016 Jan 14;115(1):95-104.

[20] Warensjö Lemming E, Nälsén C, Becker W, et al. Relative validation of the dietary intake of fatty acids among adults in the Swedish National Dietary Survey using plasma phospholipid fatty acid composition. J Nutr Sci. 2015 Jun 26;4:e25. DOI:10.1017/jns.2015.1

[21] Willett WC. Nutritional epidemiology. 2nd ed. New York (NY): Oxford University Press; 1998.

[22] Martínez-González MA. Bioestadística amigable. 3rd ed. Barcelona: Elsevier España S.L.; 2014.

[23] Franke C, Verwied-Jorky S, Campoy C, et al. Dietary intake of natural sources of docosahexaenoic acid and folate in pregnant women of three European cohorts. Ann Nutr Metab. 2008;53(3-4):167-174.

[24] Stea TH, Uglem S, Wandel M, et al. Association between folate intake from different food sources in Norway and homocysteine status in a dietary intervention among young male adults. Br J Nutr. 2009 Sep;102(6):899-906.

[25] Pounis G, Di Castelnuovo AF, de Lorgeril M, et al.; European Collaborative Group of the IMMIDIET Project. Folate intake and folate serum levels in men and women from two European populations: the IMMIDIET project. Nutrition. 2014 Jul-Aug;30(78):822-830.

[26] Simunaniemi A-M, Andersson A, Nydahl M. Fruit and vegetable consumption close to recommendations. A partly web-based nationwide dietary survey in Swedish adults. Food Nutr Res. 2009 Dec 22;53:2023.
[27] Laiño JE, Leblanc JG, Savoy de Giori G. Production of natural folates by lactic acid bacteria starter cultures isolated from artisanal Argentineanyogurts. Can J Microbiol. 2012 May;58(5):581-588. DOI:10.1139/ w2012-026

[28] Beunza J-J, Toledo E, Hu FB, et al. Adherence to the Mediterranean diet, long-term weight change, and incident overweight or obesity: the Seguimiento Universidad de Navarra (SUN) cohort. Am J Clin Nutr. 2010 Dec;92(6):1484-1493.

[29] Finger JD, Tylleskär T, Lampert T, et al. Dietary behaviour and socioeconomic position: the role of physical activity patterns. PLoS One. 2013 Nov 6;8(11):e78390. DOI:10.1371/journal.pone.0078390

[30] Conklin AI, Forouhi NG, Surtees P, et al. Gender and the double burden of economic and social disadvantages on healthy eating: cross-sectional study of older adults in the EPIC-Norfolk cohort. BMC Public Health. 2015 Jul 22;15:692.

[31] Monteagudo C, Mariscal-Arcas M, Palacin A, et al. Estimation of dietary folic acid intake in three generations of females in Southern Spain. Appetite. 2013 Aug;67:114-118.

[32] Monteagudo C, Mariscal-Arcas M, Rivas A, et al. Proposal of a Mediterranean diet serving score. PLoS One. 2015 Jun 2;10(6):e0128594.

[33] Drake I, Gullberg B, Ericson U, et al. Development of a diet quality index assessing adherence to the Swedish nutrition recommendations and dietary guidelines in the Malmö diet and cancer cohort. Public Health Nutr. 2011 May;14(5):835-845.

[34] Sobiecki JG, Appleby PN, Bradbury KE, et al. High compliance with dietary recommendations in a cohort of meat eaters, fish eaters, vegetarians, and vegans: results from the European prospective investigation into cancer and nutrition-oxford study. Nutr Res. 2016 May;36(5):464-477.

[35] Elorinne A-L, Alfthan G, Erlund I, et al. Food and nutrient intake and nutritional status of Finnish vegans and non-vegetarians. PLoS One. 2016 Feb 3;11(2): e0148235.

[36] Schüpbach R, Wegmüller $R$, Berguerand $C$, et al. Micronutrient status and intake in omnivores, vegetarians and vegans in Switzerland. Eur J Nutr. 2015 Oct;26. DOI:10.1007/s00394-015-1079-7

[37] Baudry J, Allès B, Péneau S, et al. Dietary intakes and diet quality according to levels of organic food consumption by French adults: cross-sectional findings from the NutriNet-Santé cohort study. Public Health Nutr. 2016 Oct;12:1-11.

[38] Ortega RM, Lopez-Sobaler AM, Gonzalez-Gross MM, et al. Influence of smoking on folate intake and blood folate concentrations in a group of elderly Spanish men. J Am Coll Nutr. 1994 Feb;13(1):68-72. 